Anglais de spécialité et milieux professionnels

\title{
Compétence de culture professionnelle : définition, degrés et didactisation
}

Shaeda Isani

\section{(2) OpenEdition}

1 Journals

Édition électronique

URL : http://journals.openedition.org/asp/979

DOI : $10.4000 /$ asp. 979

ISBN : 978-2-8218-0396-1

ISSN : 2108-6354

Éditeur

Groupe d'étude et de recherche en anglais de spécialité

Édition imprimée

Date de publication : 1 mars 2004

Pagination : 5-21

ISSN : 1246-8185

Référence électronique

Shaeda Isani, «Compétence de culture professionnelle : définition, degrés et didactisation », ASp [En ligne], 43-44 | 2004, mis en ligne le 13 mars 2010, consulté le 10 décembre 2020. URL : http://

journals.openedition.org/asp/979; DOI : https://doi.org/10.4000/asp.979

Ce document a été généré automatiquement le 10 décembre 2020.

Tous droits réservés 


\title{
Compétence de culture professionnelle : définition, degrés et didactisation
}

\author{
Shaeda Isani
}

1 Si la recherche en langues de spécialité s'intéresse depuis un certain temps déjà à la notion de compétence langagière, elle s'est relativement peu intéressée à la notion de compétence culturelle et, dans le contexte du GERAS, il aura fallu attendre 2002 pour que la culture soit formellement reconnue comme l'une des composantes de notre discipline par Petit dans sa définition de la discipline :

[L'anglais de spécialité est] la branche de l'anglistique qui traite de la langue, du discours et de la culture des communautés professionnelles et groupes sociaux spécialisés anglophones et de l'enseignement de cet objet. (2002:2-3)

2 Nous n'aborderons pas, dans le cadre de cette étude, le débat qui a lieu en France aujourd'hui concernant la ligne de partage entre « civilisation », la culture «savante » et la « culture » au sens anthropologique du terme, nous contentant de préciser que, dans le contexte de nos filières professionnalisantes, notre intérêt porte principalement - mais non pas de manière exclusive - sur la culture dans son acception anthropologique et expérientielle. Si nous prenons le monde de l'entreprise comme cadre de référence pour illustrer notre propos, il reste évident que tout l'intérêt de cette analyse est d'explorer sa transposabilité vers d'autres domaines d'application professionnelle.

\section{Trois compétences sous-jacentes à la compétence culturelle}

Dès 1986, dans le cadre des travaux fondateurs réalisés par le Conseil de l'Europe, Van Ek (1986: 33-37) définit cinq composantes de la compétence de communication: linguistique, sociolinguistique, discursive, stratégique et socioculturelle. Réunies, elles constituent ce qu'il appelle la compétence sociale qui sous-tend la compétence de 
communication. Dans le cadre de la définition de ce champ d'étude, nous retiendrons les trois compétences directement liées à la dimension culturelle de la communication :

- la compétence sociolinguistique

- la compétence socioculturelle

- la compétence sociale.

4 La compétence sociolinguistique ${ }^{1}$, qui repose sur une maîtrise de l'usage approprié de la langue en fonction de la spécificité de chaque situation de communication (modes d'énonciation, statut social de l'émetteur, comportements et attitudes de l'interlocuteur, jugements normatifs sur la langue), se distingue de la compétence socioculturelle, conception plus récente, qui repose sur la maîtrise des éléments culturels associés et intégrés à la langue cible.

5 La notion de compétence sociale s'avère plus problématique, car sa définition, toujours selon Van Ek, tendrait à la situer en-dehors du cadre des disciplines de la didactique des langues :

If two individuals are to co-ordinate their efforts to engage in interaction they must, at least, have the will and the skill to do. The will to interact involves motivation, attitude and self-confidence; the skill to interact involves such qualities as empathy and the ability to handle social situations. We indicate these qualities collectively as social competence. (1986:65)

6 Tout en lui reconnaissant un volet langagier important - les « techniques » nécessaires à la capacité ( « the skill ») à engager des échanges - Van Ek admet que la compétence sociale possède également un volet psychologique important. Elle est ainsi largement tributaire de la personnalité et de la volonté ( the will ») de l'interlocuteur.

7 Cette double articulation de la compétence sociale soulève des questions importantes par rapport à la didactique. Si l'acquisition des «techniques" est un objectif communicatif classique qui repose, notamment, sur le domaine de l'analyse discursive et sur les activités pédagogiques interactives (le jeu de rôle, la négociation, la résolution du problème, «question time ", etc.), le rôle des enseignements de langue dans l'acquisition par l'apprenant de la "volonté» de communiquer et de qualités comme celle de l'empathie, est une question plus complexe même si elle peut prendre toute sa pertinence dans une redéfinition des rôles enseignant / apprenant fondée sur la valorisation de l'apprenant et la perception par celui-ci de la salle de classe comme un environnement sécurisant.

8 Cette étude rapproche nos propres considérations relatives au domaine des langues et des cultures de spécialité des travaux de Van Ek. Notre intérêt porte plus particulièrement sur le volet socioculturel de la compétence sociale définie par Van Ek que nous situons dans le cadre plus précis du monde de l'entreprise. Dans un objectif de mieux comprendre la notion de compétence de culture professionnelle, nous nous proposons d'analyser les différents éléments constitutifs d'une telle culture pour ensuite examiner la possibilité de définir une échelle de degrés relative à une compétence de culture professionnelle.

\section{Quelques composantes d'une « culture professionnelle»}

9 Nous partons du double postulat que toute étude de ce type est fondée sur le rejet de l'acception monolithique de la culture pour s'intéresser au caractère complexe et 
composite de sa construction et, d'autre part, que toute culture professionnelle se construit à partir et sur la base de ce que nous appelons « la culture idiolectale ».

\subsection{La notion de culture idiolectale}

10 Nous nous sommes permis d'extrapoler le concept linguistique de l'idiolecte au domaine de la réflexion sur l'identité culturelle pour désigner ce qui, dans la culture, est spécifique à l'individu, la somme de tout son vécu (familial, sexuel, générationnel, éducatif, etc.) et que nous avons défini ailleurs comme suit :

La culture sui generis est au domaine de la culture ce qu'est un idiolecte au domaine des langues : l'appropriation - et donc la «déviation »- d'une culture à travers le prisme subjectif de sa propre vision et de son propre vécu. Poussée à son expression extrême, la culture personnelle devient excentricité, mais en quantité homéopathique, ce qui est la norme, elle sert à démarquer les différents membres d'une même communauté les uns des autres. (Isani \& Andréolle 2001 : 227-228)

11 L'analyse de l'identité culturelle à ce niveau repose généralement sur trois angles d'entrée classiques :

- la dimension psychologique liée à l'histoire personnelle de l'individu ;

- la dimension sociologique liée à son appartenance à un groupe social défini possédant des caractéristiques communes identifiables ;

- la dimension ethnologique liée à son appartenance à une culture d'origine et/ou une culture d'adoption.

12 Cette culture idiolectale constitue les fondations sur lesquelles se greffent d'autres composantes qui relèvent d'une appartenance culturelle collective et professionnelle. Si l'analyse classique permet de dessiner les traits larges de l'identité culturelle au niveau idiolectal, elle ne permet pas de rendre compte de toute la diversité des différents héritages liés aux différences collectives qui entrent en jeu dans la construction d'une identité culturelle professionnelle. Pour mieux rendre compte de l'ensemble du patrimoine culturel dont le professionnel est porteur, l'analyse doit s'étendre également à d'autres sources d'influence collective.

13 Ainsi, en partant de la culture idiolectale comme la base sur laquelle se greffent d'autres composantes relevant d'une appartenance culturelle collective et professionnelle, nous avons pu, dans le cadre de l'entreprise, identifier cinq aires principales qui méritent analyse.

\subsection{Culture de travail nationale}

Une culture de travail se définit à deux niveaux. À un premier niveau, la culture de travail nationale peut être définie à travers un cadre de référence concrètement observable, l'organisation sociale et juridique du travail : les heures et la durée du travail, l'âge de la retraite, l'indexation des salaires, le travail des enfants, le concept et le nombre de congés payés, etc.À ce niveau, nous citerons, à titre d'exemple, les perceptions existant par rapport à la culture de travail nationale en France, qui fut décrite par le New York Times lors de l'entrée en vigueur de la loi concernant les 35 heures, comme le pays où «If today's not a holiday, tomorrow will be ".

Mais il existe également des divergences qui se situent à un deuxième niveau plus implicite, moins visible, celui des perceptions et représentations plus générales. Un 
exemple très parlant serait le travail perçu comme activité valorisante ou non. Il existe certaines cultures où le statut social va de pair avec le statut financier: si l'on est "quelqu'un", on est riche; au quel cas, on n'a pas besoin de travailler; travailler c'est donc le sort réservé aux démunis, une notion que nous pouvons trouver plus proche de nous que l'on ne le pense puisqu'il existe encore aujourd'hui des cultures européennes où le fait qu'une femme travaille est perçu comme « déshonorant pour son mari ».

\subsection{Culture d'entreprise}

Bernard fournit la définition suivante de la culture d'entreprise :

Telle qu'elle est aujourd'hui comprise, la culture d'entreprise consiste en principes plus ou moins clairement exprimés, en conduite du métier, accomplissement de la vocation, règles de conduite, normes de comportement, attitudes en réponse à des situations données. Elle est faite de valeurs idéologiques, morales et professionnelles, de conceptions de base, croyances fondamentales plus ou moins bien perçues qui constituent le «subconscient» de la firme. (1994 cité dans Lehmann : 19)

Ce qu'il est important de retenir par rapport à la culture d'entreprise est qu'il ne s'agit pas d'un phénomène spontané, émanant de la conscience collective d'une communauté professionnelle, mais d'une "culture " fabriquée, développée et imposée par les dirigeants en vue de créer une cohésion interne, un sentiment d'appartenance qui aidera à « fédérer, mobiliser, gommer les différences entre les catégories de personnels au profit de la réalisation des missions de l'entreprise » (Thévenet 1994 : 6).

Alors que nombreuses sont les entreprises qui ont une culture d'entreprise discrète, d'autres font le choix d'une culture d'entreprise forte et visible, clairement explicitée, qui fait l'objet d'une large communication à l'intérieur et à l'extérieur de l'entreprise, comme celles, plus médiatisées, de McDonald's, IBM, Hewlett Packard, Ikea et Peugeot. D'importantes recherches dans ce domaine (Hall 1971, d'Iribarne 1989) font état d'une forte congruence entre cultures nationales et cultures d'entreprise, ce qui explique les difficultés que l'on observe à l'exportation de ces modèles dans d'autres cultures que celles qui les ont créées.

\subsection{Culture de corporation}

Une autre composante collective de la culture professionnelle vient de la culture de corporation. Ce niveau de culture fédère tous les professionnels issus de la même "discipline mère ", si l'on peut dire, mais qui exercent leur métier dans des lieux et des organisations exogènes par rapport à leur discipline première, comme par exemple, le juriste d'entreprise, le médecin du travail ou encore l'enseignant exerçant dans le centre de formation d'une entreprise.

À cet égard, le caractère exogène que peut revêtir une culture de corporation par rapport à celle qui définit les salariés de l'entreprise trouve son équivalent dans le monde universitaire, comme on peut le constater à travers la situation de la grande majorité des enseignants de langues de spécialité qui exercent dans des établissements autres que ceux de leur discipline. 


\subsection{Culture de service}

21 On peut partager une culture d'entreprise sans pour autant partager la même culture de service. Selon les services, les cultures peuvent être très différenciées, voire contrastées. Un exemple frappant de cette divergence est la différence qui existe entre la culture du service achats et celle du service vente. Ces deux services co-existent au sein d'une même entreprise mais se distinguent fortement dans la mesure où le premier a affaire à des fournisseurs et donc se positionne en tant que client, alors que le deuxième a affaire à des clients et se positionne donc comme fournisseur, deux positionnements qui engendrent des différences marquées sur le plan de la représentation et du comportement professionnels.

\subsection{Culture de fonction}

La culture de fonction est transversale par rapport à l'organisation structurale de l'entreprise, dans la mesure où les individus qui la véhiculent se trouvent dispersés dans différents services, agences et filiales. Ainsi, nous avons une culture de cadres ou une culture de secrétaires, une culture de chercheurs et une culture d'ouvriers etc., toutes ces cultures possédant des valeurs qui ne sont pas simplement différentes mais parfois très divergentes.

La Figure 1 permet d'illustrer le caractère composite et la construction centripète de cette culture professionnelle et de mieux comprendre que la convergence de ces nombreux faisceaux, parfois très divergents, peut contribuer à transformer en tour de Babel culturelle même une simple rencontre dyadique en milieu professionnel.

Fig. 1. Quelques composantes de la culture professionnelle

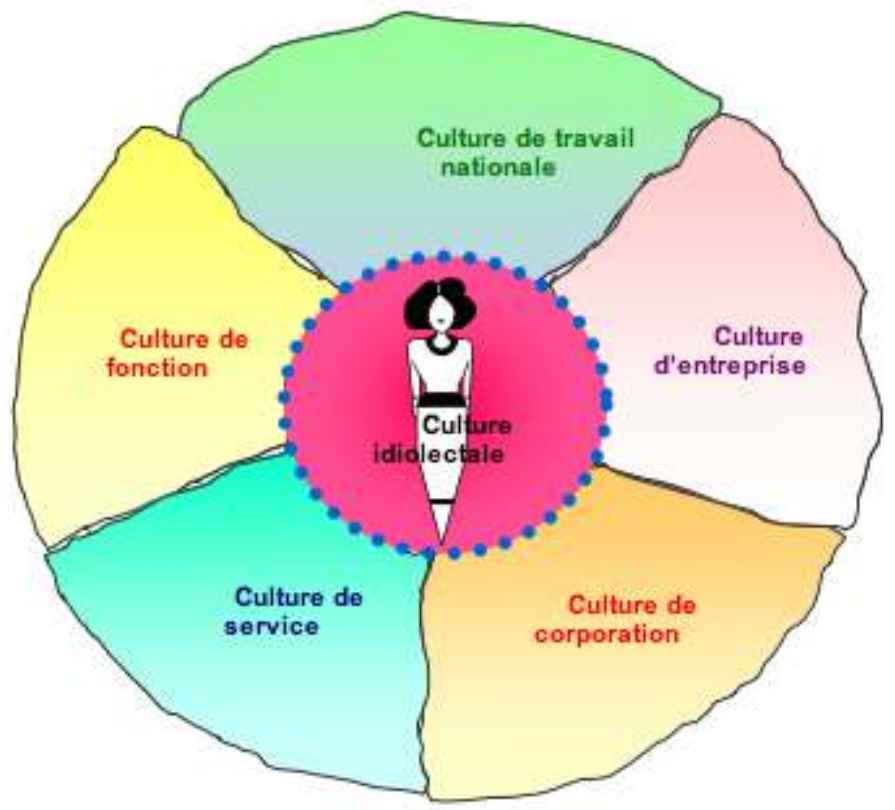

Cette complexité explique peut-être aussi pourquoi c'est la langue qui a toujours été privilégiée comme objet d'étude plutôt que sa culture! La langue se prête mieux à 
l'analyse, la conceptualisation, la codification, la classification et ainsi à la didactisation. La culture, en revanche, est un domaine si vaste, si amorphe, si labile et si contradictoire parfois, qu'elle résiste à la dissection de l'analyse scientifique. Mais notre problème, c'est que pour pouvoir l'enseigner, il faut la conceptualiser, il faut la didactiser et il faut pouvoir l'évaluer. Et pour cela il nous faut des outils d'analyse qui permettent de transformer cette nébulosité en objet d'étude. C'est dans le but d'amorcer la réflexion dans ce domaine que nous nous proposons d'ébaucher une échelle de degrés de compétence en culture professionnelle.

\section{Degrés de compétence en culture professionnelle}

La recherche dans ce domaine en France relève essentiellement de deux courants, d'une part, les travaux des didacticiens FLE et, d'autre part, ceux des chercheurs en sciences sociales qui s'intéressent au milieu professionnel interculturel. En partant d'une synthèse des principaux travaux produits jusqu'à aujourd'hui, il nous a semblé utile d'entreprendre, à des fins didactiques, une première ébauche de ce qui pourrait évoluer vers la définition des différents degrés d'une compétence de culture professionnelle. Tout en soulignant le caractère in vitro de l'exercice - pourrait-il en être autrement compte tenu de la nature même de l'objet d'étude ? - nous nous proposons d'organiser cette compétence sur une échelle de sept degrés de complexité.

\subsection{L'éveil : la sensibilisation à l'altérité}

Quelles que soient leurs divergences par ailleurs, tous les chercheurs s'accordent pour souligner l'importance de cette phase préliminaire : l'éveil à la différence culturelle. Il s'agit d'une étape de sensibilisation qui se situe habituellement au stade des premières socialisations de l'enfant à l'école et est déterminante par rapport à la façon dont le futur adulte va construire et gérer ses représentations de l'altérité. Trop longtemps tributaire des aléas des représentations véhiculées par l'environnement immédiat de l'enfant, ce n'est que tardivement que l'école a reconnu l'importance de prendre en charge l'orientation de cette première rencontre avec l'altérité culturelle et, aujourd'hui, nous assistons à la banalisation de l'éveil aux langues étrangères en cours préparatoire.

\subsection{Le savoir culturel : la connaissance in vitro}

Tous les avis s'accordent également pour reconnaître l'existence de ce niveau de compétence, qui se définit en termes de la culture conçue comme un savoir théorique. Il repose sur des informations et des faits culturels, dont la somme constitue un savoir encyclopédique qui repose sur des données stables et observables.

Dans le domaine de la didactique, on peut identifier deux approches principales par rapport à ce degré de compétence culturelle: une première qui s'intéresse à l'aspect « civilisationnel » de la culture (les événements, les institutions et les figures historiques qui ont marqué le pays), et une deuxième qui s'intéresse à l'étude ethnométhodologique ${ }^{2}$ de la vie quotidienne des habitants, dans ce qu'elle représente de "typique». Les deux approches font l'objet de débats académiques en France et à l'étranger. L'approche " civilisationnelle ", très présente dans la didactique universitaire française, est parfois perçue, notamment par les Nordiques, comme étant inadaptée au profil des apprenants 
LEA et à la finalité professionnelle de leur apprentissage et, aujourd'hui, une réflexion s'engage sur la finalité et les contenus des enseignements relevant de cette approche. L'approche ethnométhodologique est également mise en cause car perçue non seulement comme étant réductrice et vecteur de stéréotypes, mais également comme " nationaliste ", dans la mesure où elle privilégierait « mainstream culture.

La question que pose l'existence de ces deux courants est de savoir s'ils sont aussi hermétiques que certains le supposent. Restreindre la culture à un enseignement purement théorique, qui se donne comme objectif l'acquisition de connaissances relatives aux institutions de la Grande-Bretagne, par exemple, conviendra sans doute mieux aux attentes des étudiants de la filière "publique » de Sciences Politiques. En revanche, un enseignement qui vise l'acquisition de connaissances relatives aux aspects quotidiens et matériels de la vie d'une communauté risque d'être simplement utilitaire et consumériste. Pour rendre à la culture sa dimension à la fois pragmatique et intellectuelle, les deux cultures doivent, nous semble-t-il, être fusionnées. Cette vision « civilisation-culture » trouve l'une de ses expressions dans le Dictionary of Britain, dont les objectifs et le champ d'étude sont définis par Room, son auteur :

The Dictionary of Britain gives up-to-date information on all aspects of British life and institutions. It explains everything that other nationalities find interesting, amusing, puzzling or even frustrating about Britain and the British. Important public events, major government posts, and well-known organizations of all kinds are described. Also included are events, institutions and people that show a typically British set of values or an important facet of British life. Entries on regional foods shed light on the culinary variety within Britain, while description of sports, crafts and societies show what the British do in their spare time. (1987:v)

Pour conclure sur ce degré de compétence, on rappellera que les modes et processus d'acquisition de ce degré de compétence culturelle sont essentiellement cognitifs et, à ce titre, il importe de noter que son acquisition ne nécessite pas une connaissance de la langue cible. Cette particularité trouve son écho, d'ailleurs, dans la problématique qui sous-tend l'évaluation des enseignements de "civilisation" dans nos cursus et la définition de l'objet de l'évaluation : langue ou contenu, expression ou connaissances?

\subsection{Le savoir-faire culturel : le fonctionnel}

31 Bien que la compétence culturelle soit à prendre dans une acception holistique et transversale à toutes les dimensions de la vie socio-professionnelle, elle peut, comme c'est le cas pour les langues, être appréhendée dans des contextes d'utilisation précise, rappelant l'approche fonctionnelle de la didactique des langues des années 1980.

Pris dans cette acception, le savoir-faire culturel - terme utilisé parfois pour désigner la compétence culturelle elle-même - se situerait au niveau utilitaire et définirait la capacité de fonctionner efficacement dans un environnement étranger en accomplissant les tâches de la vie quotidienne, comme par exemple, faire ses courses, s'orienter et se déplacer, gérer les relations de service, gérer les rendez-vous, connaitre les horaires de travail, les jours fériés, les rythmes socioprofessionnels (heures des repas, heures de travail, ouverture des magasins, heures de pointe, etc.), se conformer aux normes et pratiques qui régissent la vie civile (poubelles, stationnement, arrosage, chiens, etc.), ou professionnelle (pointage, sécurité, cantine, pauses-café, téléphone, etc.).

33 L'aspect fonctionnel de la notion de savoir-faire culturel est facile à comprendre pour nous, enseignants, lorsque nous comparons nos étudiants de première année - à qui il fait 
cruellement défaut - à ceux de deuxième année, bien plus acculturés et autonomes par rapport à ce que Gohard-Radenkovic (2002:12) appelle « le métier de l'étudiant ».

Comme la notion de savoir culturel que nous venons de décrire, celle du savoir-faire culturel s'appuie moins sur une compétence en langue que sur l'identification de repères à l'intérieur d'un système de fonctionnement. À cet égard, on peut même constater un phénomène d'inversion par rapport aux progrès réalisés dans les deux domaines, fonctionnel et langagier : plus un individu avance dans sa maîtrise du savoir-faire culturel relatif à son environnement immédiat, moins il perçoit la nécessité de développer ses compétences langagières, ce qui conduit au phénomène de fossilisation linguistique bien répertorié.

L'absence de ce savoir-faire culturel et les dysfonctionnements qui en résultent sur le plan de l'intégration dans la vie culturelle de l'environnement quotidien ont donné naissance au nouveau métier de médiateur culturel(Bolaffi, Bracalenti, Braham \& Gindro 2003 : 51), encore mal connu en France, mais largement utilisé dans d'autres pays (l'Italie et le Royaume-Uni, par exemple), où il est déployé dans des lieux stratégiques de la rencontre interculturelle, comme les mairies, les centres de sécurité sociale, les offices de tourisme, les entreprises multinationales à forte population d'expatriés et, bien entendu, les universités.

\subsection{Le savoir-vivre culturel : l'adaptation verbale et non-verbale}

Le savoir-vivre culturel se situe au niveau plus complexe de l'interaction avec l'Autre, en tant que sujet parlant, et demande ainsi un travail d'adaptation dans le domaine discursif, sur le plan du verbal aussi bien que celui du non-verbal. Au niveau réduit de l'interaction simple, ces échanges peuvent porter sur les salutations (verbales et gestuelles), la formulation d'excuses, d'explications, l'observation des conventions du code vestimentaire, et l'observation des conventions implicites de temps (la ponctualité), de la proxémique (respect de l'espace interpersonnel, interprétation de la porte fermée), etc. $\mathrm{Au}$ niveau plus complexe, cette étape s'étend à la maîtrise de registres langagiers appropriés, au respect des conventions de table, à l'évitement des zones de tensions, etc.

\subsection{Le savoir-être culturel : l'adaptation psychologique}

Le savoir-être culturel représente l'étape de l'intégration de l'altérité. Sans pour autant quitter son propre habitus culturel, l'individu développe une attitude moins spontanément ethnocentrique, fondée sur l'écoute.

Curieusement, l'acquisition de cette dimension de la compétence culturelle repose souvent sur la découverte de sa propre culture, suite à une confrontation à la culture de l'autre, comme l'affirme Laurent, professeur de psychologie :

Le conditionnement culturel est si fortement enraciné en chacun de nous qu'en l'absence de contact avec une autre culture on ne peut découvrir qui l'on est. [...] Sur le plan de l'interculturel, on a besoin de la découverte de l'autre pour se repérer, s'identifier, se connaître et devenir conscient de la manière d'être en tant qu'individu appartenant à une culture. (1998: 39)

Ce nouveau regard sur sa propre culture s'accompagne d'une sensibilisation à la réciprocité de la différence en rencontre interculturelle: «Si l'autre me dérange, je le dérange aussi ! ». 
De telles prises de conscience favorisent l'acquisition d'une capacité à relativiser sa propre culture à l'aune des perceptions que l'Autre en possède, une mise en perspective quasi "déictique », qui permet d'éviter le type de cécité que décrit Desjeux, professeur de psychologie de l'organisation :

Pour un Français, arriver en retard d'une quinzaine de minutes à une réunion de travail est «normal » et fait partie des codes culturels, ce qui n'est pas le cas pour un Allemand qui le traduit par un manque de considération à son égard. Mais si j'écoute un Français parlant d'un Africain, il me dira que les Africains sont toujours en retard et que c'est un manque de considération parce que cela rend l'organisation de la journée impossible. (1998: 94)

Cette étape peut être mise en parallèle avec ce que Brace-Le Bigot identifie comme l'étape finale, celle du « disengagement » :

Investing cross-cultural enquiry with a personal commitment on the part of the learner in no way implies denial of one's own culture. It simply means being able to disengage oneself from a number of attitudes which have previously remained unquestioned in order to be "free" to examine (and perhaps adopt) alternatives. Disengagement involves a willingness to take the risk of exposing to question that which has been a source of protection, comfort and security. (1994:221)

\subsection{Le savoir-agir culturel : sur ou avec?}

42 La réflexion a, jusqu'ici, essentiellement porté sur le cadre "général », où l'acquisition d'une compétence culturelle s'insère dans des objectifs éducatifs gouvernés par une forte motivation d'intégration. Dans le contexte de la didactique des langues et des cultures de spécialité, cependant, de telles vocations peuvent paraître relever de l'angélisme car, si la motivation d'intégration s'y profile en filigrane (intégration dans une communauté de discours), la motivation principale est fortement instrumentale et utilitaire, et se définit par le désir d'agir sur l'Autre, pour réussir un projet professionnel, imposé ou choisi, collectif ou personnel, comme le dénoncent les chercheurs autrichiens Klingseis, Rathmayr \& Schmid :

The main goal of research conducted in this area [intercultural management, intercultural communication, intercultural training / coaching] seems to be to provide economists with pragmatic little units of so called "(inter-)cultural knowledge" enabling them to perform better in international business negotiations, i.e. training them how to behave, how to act, what to say and what not to say in order to achieve successful business deals faster and easier, avoiding possible embarrassing situations when negotiating with business partners from "another culture". (1997, communication en ligne)

43 Prise dans cette perspective, la compétence culturelle - compréhension de la culture de l'Autre et des effets de sa propre culture sur l'Autre - s'insère dans une approche pragmatique, ancrée dans les concepts de l'acte, du contexte, de la performance et de l' opérationnel, à situer dans la réalisation des tâches et des objectifs professionnels ciblés. Dans ce contexte, il peut se produire une instrumentalisation de la compétence culturelle, dont le contrôle échappe à ses créateurs. Selon le domaine professionnel - le monde des affaires tel qu'il est incarné par Gekko ${ }^{3}$ ? - cette compétence culturelle peut se transformer en redoutable outil destiné à la manipulation de l'Autre, restituant au terme « interaction » sa signification en psychologie sociale, celle de la volonté d'influencer l'Autre.

À cette conception du savoir-agir sur, nous préférons celle proposée par Puren « le savoiragir avec ». Il s'agit d'une approche à la fois plus en adéquation, sur le plan moral, avec les 
objectifs qui se veulent éducatifs et, sur le plan didactique, plus en phase avec les objectifs des langues et des cultures de spécialité. Dans une double perspective, qu'il appelle coactionnelle/co-culturelle, et qu'il propose comme la nouvelle perspective de l'approche communicative, Puren situe l'acquisition d'une compétence culturelle, non pas au niveau des savoirs, mais dans le domaine des habitudes et des comportements à acquérir en travaillant avec l'Autre, dans l'accomplissement des objectifs concrets, nécessaires et communs aux deux.

Mais lorsqu'il s'agit non plus seulement de "vivre ensemble " (co-habiter ou coexister), mais de «faire ensemble » (co-agir), nous ne pouvons plus nous contenter d'assumer nos différences: il nous faut impérativement créer ensemble des ressemblances. Or cette modification de l'objectif culturel de référence exige rien moins que de passer en didactique de la culture d'une « langue produit » [...] à une «logique processus» qui se trouve être plus conforme à une représentation moderne, c'est-à-dire dynamique, des réalités culturelles. Il est évident qu'on n'a pu se focaliser à ce point jusqu'à présent, dans la perspective interculturelle, sur le thème de "l'altérité ", que parce que n'y était pas envisagée prioritairement l'action commune, laquelle exige de se forger des conceptions identiques, c'est-àdire des objectifs, principes et modes d'action partagés parce qu'élaborés en commun par et pour l'action collective. (2002:62)

\subsection{Le savoir-interpréter culturel : l'analytique}

Zarate (1986: 73) et Beacco (2000: 127) identifient un degré de compétence culturelle interprétative, qui permet de donner du sens social à des éléments de l'environnement, à partir de la lecture d'indices. Existant à un degré plus ou moins élevé, plus ou moins conscient chez le natif, par rapport à son propre environnement culturel, l'acquisition d'une compétence culturelle interprétative relative à l'environnement étranger permet d'opérer les mêmes analyses, par rapport à la culture étrangère. Ainsi, cette compétence permettrait de "lire» un paysage ou un environnement urbain (quartier ancien, populaire, commerçant, etc.), de situer une personne inconnue (aspect vestimentaire, comportement gestuel, accent, etc.), comme le résume Beacco :

Cette capacité d'interpréter un fait isolé peut être représentée sommairement sous forme de localisation d'une donnée à partir de systèmes de coordonnées : attribuer un âge à quelqu'un, caractériser ses opinions politiques ou ses convictions religieuses, faire des hypothèses sur son niveau de formation ou ses revenus suppose de se rapporter à une échelle de localisation, sans statut scientifique, mais fondée dans la socialisation et l'expérience. (2000:127)

Si Beacco lui-même met en garde contre la subjectivité du prélèvement des indices et le conditionnement affectif, voire idéologique, de leur interprétation, il défend cette « compétence sociale du social »comme étant culturellement attestée et observable. Pour notre part, nous ajouterons également que, compte tenu du degré d'intimité qu'elle exige, il s'agit d'une compétence qui est nécessairement limitée à une aire culturelle relativement restreinte à la fois dans le temps et dans l'espace.

La Figure 2, représentée sous forme de pyramide, permet de mieux appréhender la notion de progression qui sous-tend les sept degrés de compétence culturelle, générale ou professionnelle, que nous venons de décrire, l'éveil représentant le bout étroit de l'iceberg et le savoir interpréter culturel représentant la compréhension très fine d'une aire culturelle déterminée qui subsume les autres degrés de compétence culturelle. 


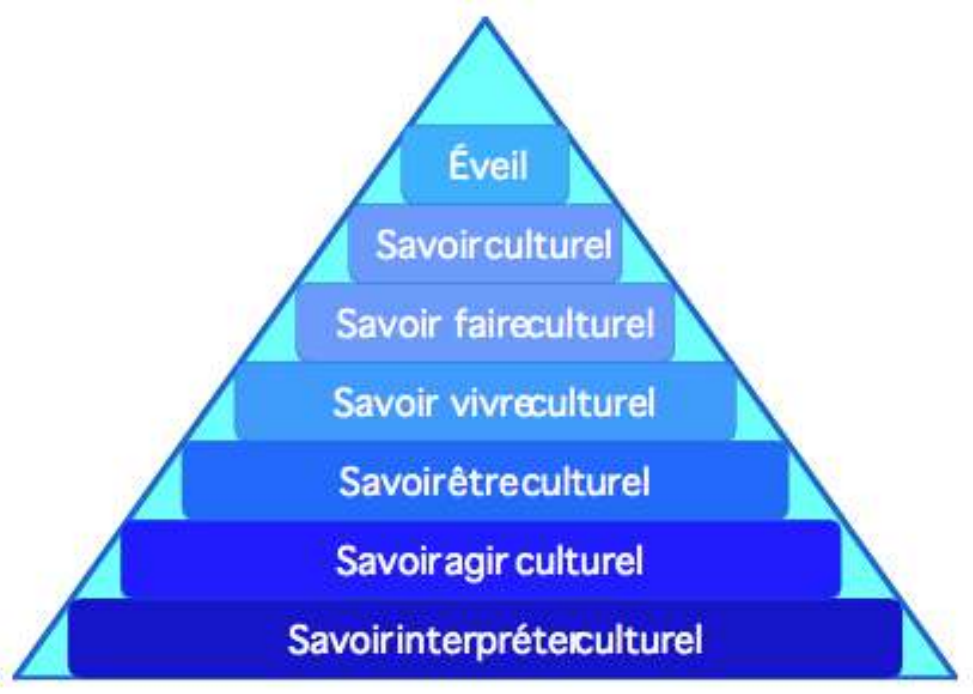

Pour terminer sur ce point, il importe de souligner que la progression linéaire de ce descriptif des différentes étapes du processus d'acculturation et sa conceptualisation sous forme d'une échelle de degrés d'une compétence de culture est un exercice " artificiel ", créé dans un but d'analyse. Il est évident que, de par la nature même de l'objet d'étude, il ne peut y opérer une progression linéaire selon laquelle les différentes étapes décrites existeraient chez l'individu en tant qu'étapes culturelles délimitées, entièrement acquises ou complètement vierges. La construction et l'acquisition d'une compétence culturelle se fait, de manière parcellaire, erratique et imprévisible, en fonction des antécédents de l'individu, du contexte pragmatique, mais aussi et surtout, des sables mouvants des perceptions et des représentations, du moi et de l'Autre, de l'ici et du là-bas.

\section{Didactisation de la culture professionnelle : quelques interrogations}

Compte tenu de ces éléments, se pose la question de la transformation de la culture, générale ou professionnelle, en objet d'enseignement-apprentissage. Nous avons déjà eu l'occasion de définir ailleurs la salle de classe des langues de spécialité comme lieu de convergence de multiples faisceaux culturels, souvent divergents et contradictoires, voire conflictuels (Isani \& Andréolle 2001). Dans le même axe de réflexion, nous faisons état ici d'un certain nombre d'interrogations plus spécifiques à la didactisation des cultures de spécialité.

\subsection{Acquisition par l'enseignant de langue d'une compétence de culture professionnelle qui n'est pas la sienne}

50 Il s'agit d'une problématique qui pose les mêmes questions et soulèvent les mêmes difficultés que l'acquisition d'un savoir relatif au domaine de spécialisation de 
l'apprenant - le droit, l'économie, la médecine, la géologie, etc. - par l'enseignant des langues de spécialité.

Nombreux sont les chercheurs qui constatent que la recherche connait un certain retard dans le domaine de l'exploration des cultures de spécialité. Une des raisons qui expliquent cette carence est peut-être la difficulté d'accès aux données. Comme nous l'observons ailleurs (Isani 2001: 7-9), l'enseignant de langues de spécialité est, à quelques rares exceptions près, rarement issu du domaine professionnel ou disciplinaire dont il enseigne la langue. Des modes d'acquisition comme l'observation in situ qui étaye l'approche empirique ou encore la démarche de suivre ("shadow») des professionnels en les observant dans la réalisation de leurs tâches professionnelles, comme le suggèrent Dudley-Evans \& St John (1998: 70), ne sont malheureusement, pas simples. Ce qui n'est pas sans engendrer des problèmes d'accès au savoir, comme le souligne Lehmann à propos de l'enseignant du français langue de spécialité :

Toute information concernant les comportements professionnels ayant cours dans tel pays, telle profession, tel groupe social, telle entreprise, revêt un intérêt d'autant plus grand que le « monde du travail, comme on dit parfois en pensant à celui de l'usine, du commerce, de l'entreprise en général, est le plus souvent parfaitement étranger à l'enseignant, y compris dans son propre pays, surtout l'enseignant littéraire. Il en ignore les règles et les codes, ce monde est pour lui un mystère quasiment indéchiffrable. On voit d'ailleurs, bien là la dimension du problème: l'enseignant du français spécialisé devra d'abord mener à bien une acculturation personnelle (intraculturelle si l'on veut) avant d'être en mesure de favoriser chez les apprenants avec qui il travaillera une autre acculturation, interculturelle celle-là. (1993:13)4

52 Tenter de s'«acculturer », par le biais de l'acquisition des théories et des données existantes, soulève à nouveau la problématique récurrente du degré d'investissement de l'enseignant de langues de spécialité dans la constitution de son capital de savoir disciplinaire Un enseignant d'anglais, travaillant avec un public d'étudiants juristes et confronté au besoin d'intégrer la composante culturelle de ce domaine professionnel à ses enseignements, doit-il, en plus de son savoir triptyque déjà existant - langue, littérature et/ou didactique, discipline d'application -, s'atteler à la découverte d'une quatrième discipline, celle du domaine des études culturelles ? Confrontée à ce dilemme et, suite à des tentatives d'initiation aux principales théories prévalant dans ce domaine passionnant, mais dont l'interdisciplinarité le rend sans limites, nous avons conclu que devenir le caméléon du savoir n'était pas une démarche très réaliste ${ }^{5}$.

Se pose alors le problème de trouver une approche apte à fournir un cadrage épistémologique à notre démarche. Notre quête nous a conduite à explorer les théories qui sous-tendent la notion de communication vicariale, champ d'étude du domaine des sciences de la communication et que Moles présente comme suit :

Si nous désirons savoir ce qui se passe au Biafra ou sur un chantier à Bruxelles, notre premier geste n'est pas de commander un billet d'avion, mais d'ouvrir notre récepteur de télévision ou de décrocher notre téléphone et nous obtenons une grande partie des renseignements que nous désirons connaître : ce n'est pas une participation totale à l'événement, mais elle est suffisante pour que nous participions aux sensations, aux émotions, aux réactions de notre correspondant, elle vient ajouter dans la sphère du récepteur, l'ensemble des stimuli présents à l'individu émetteur, témoin qui nous transmet une part, une image, des sensations qu'il subit au lieu où il est. (1971: 116)

54 Ainsi, se substitue à l'observation en présentiel, in situ et de source première, l'observation vicariale par communication médiatisée. Il est réconfortant de voir ainsi 
légitimées, sur le plan théorique, des méthodes d'accès et de collecte de données relatives aux savoirs accessoires traditionnellement pratiquées par les enseignants de langues de spécialité.

\subsection{L'enseignant de langue comme vecteur de concepts culturels} tant que personne sont probablement plus déterminantes, par rapport à la dimension culturelle, que la dimension langagière de son activité. Les raisons qui expliquent ceci sont d'ordre double et concernent, de la même manière, l'enseignant natif et le non-natif. La première concerne la relative pénurie de sources pédagogiques consacrées au volet culturel de la langue cible, ce qui fait de l'enseignant la seule source d'information devant la classe de langue. La deuxième raison est liée à son statut : il représente bien entendu le savoir, mais il est, en outre, culturellement rehaussé par l'aura du vécu, d'une expérience de première main, que ses jeunes interlocuteurs lui envient: il a été «là-bas »! Nous citons, à cet effet, Beacco :

Le mode de présence le plus commun est celui d'une représentation de la culture autre au moyen du discours: discours que tient l'enseignant. [...] Dans ce cas, l'enseignant n'est plus, comme du côté de la langue, limité au rôle de locuteur interchangeable dont les caractéristiques individuelles sont peu pertinentes pour l'enseignement / apprentissage. [...] Il est producteur d'un discours de divulgation didactique qui n'a pas grand chose en commun avec les processus de formation au langage. Le professeur de langue est aussi susceptible d'assumer un rôle de témoin, parlant alors en son propre nom, sans que ce discours à la première personne soit toujours nettement distingué d'un discours informatif non personnel. Il intervient alors à partir de son expérience de cet autre monde. (2000:67)

D'où le danger. En tant que seul dépositaire et arbitre de cette dimension culturelle, il se peut qu'il y ait dérive: que l'enseignant, dont la propre expérience est peut-être parcellaire ou biaisée, devienne le vecteur de stéréotypes ou de mythes, qu'il y ait des interférences de sa culture idiolectale sur les représentations qu'il véhicule de la culture cible (Isani \& Andréolle 2001 : 228-236). Il peut arriver aussi qu'il y ait minoration de la culture étrangère par rapport à la culture d'origine, ou vice versa. Plus grave encore, il peut y avoir une exploitation, consciente ou non, de l'auditoire captif que constituent les apprenants, à des fins d'enculturation et de prosélytisme, selon des convictions personnelles, politiques, religieuses et morales (Isani 2004).

Il existe cependant des contrepoids, notamment une meilleure prise en compte dans la formation des enseignants, des procédures de distanciation et d'analyse par rapport aux représentations culturelles. Il y a également, aujourd'hui, une certaine «militance interculturelle » fondée sur un éveil croissant aux notions de culturalité, né des formes directes (voyages) et indirectes (média) du contact culturel. Mais il y a, surtout, l'introduction des modules d'enseignements d'interculturalité dont l'objectif devrait résider moins dans l'acquisition des connaissances liées aux différences culturelles que dans l'acquisition d'outils conceptuels permettant d'analyser les différences, de distinguer entre celles qui relèvent de la culture collective et celles qui relèvent de la personne et, enfin, d'ajuster ses propres comportements en conséquence. Il importe à cet égard, de souligner la nature transversale, et donc transposable, d'un tel objectif qui se situe d'abord sur le plan de la démarche personnelle et ensuite seulement, sur le plan d'un domaine disciplinaire / professionnel ou d'une aire géographique. 


\subsection{Le rôle des stéréotypes culturels et le culturalisme} (Abdallah-Pretceille 1991; de Nucheze 2001) situent leurs théories dans cette tendance culturaliste qui fait proliférer et perdurer des stéréotypes culturels, comme l'illustrent ces propos de Hall, extraits de La dimension cachée, au sujet des Français et de l'espace :

Le rapport des Méditerranéens avec l'espace se révèle dans leurs trains bondés, leurs autobus, leurs cafés, leurs autos et leurs demeures. [...] Le fait que beaucoup de Français disposent de peu de place explique en partie le plaisir qu'ils semblent avoir à vivre hors de chez eux. Le Français reçoit au café et au restaurant. La maison est réservée à la famille, les lieux extérieurs sont consacrés aux distractions et aux rapports sociaux. D'après ma propre expérience et celles qui m'ont été rapportées, les logements sont souvent surpeuplés. C'est surtout vrai pour la classe ouvrière et la petite bourgeoisie avec pour conséquence un rôle important de la sensualité dans les rapports interpersonnels. (1971: 177)

61 Même en situant de telles analyses dans le contexte des années soixante, il est à se demander si des trains et des autobus bondés représentent un choix culturel ou une réalité économique? Ou comment des gens dont les logements sont "surpeuplés» peuvent se permettre de recevoir au café et au restaurant? Et finalement, si cette sensualité, dépeinte comme spécifique des rapports interpersonnels en France, est due à l'exiguiité des logements, pourquoi les Japonais, qui ont pourtant inventé la chambre capsule, ne sont-ils pas aussi des sensuels?

De la même façon, dans un chapitre relatif à l'organisation proxémique en milieu professionnel, Hall présente l'analyse suivante des traits spécifiques aux salariés américains :

Aux États-Unis, votre adresse privée comme celle de votre travail contribuent de façon importante à votre statut social. [...] Les firmes installées dans Madison ou Park avenue sont supérieures à celles de la Septième ou de la Huitième avenue. Un bureau d'angle est plus prestigieux qu'un bureau situé près d'un ascenseur ou à l'extrémité d'un couloir. (1971:170) 

françaises - ainsi que celles du reste du monde - préfèrent également avoir leur siège à Neuilly plutôt qu'à Barbès et n'importe quel cadre, français ou autre, préfèrerait également un bureau éloigné de l'ascenseur et des toilettes.

Des analyses de ce type, qui partent des observations, somme toute assez banales et triviales, d'une aura scientifique, créent et font perdurer des stéréotypes souvent obsolètes, erronés, exagérés, voire même contradictoires, comme c'est le cas de deux traits culturels «observés» par Hall concernant l'organisation de la proxémique interpersonnelle chez les Arabes: «Dans la conversation, les Arabes vous tiennent toujours dans le champ de leur haleine. [...] Respirer l'odeur d'un ami est non seulement agréable mais désirable, car refuser de laisser respirer son haleine est un signe de honte " (1971 : 196). Et, à la page suivante, «Les Américains commettent souvent l'erreur de croire que les Arabes parlent toujours de très près à leur interlocuteur » $(1971: 197)$.

$\mathrm{Si}$ des observations fondées sur un stéréotype de ce type sont à dénoncer catégoriquement, la question reste posée par rapport aux stéréotypes relevant de la surgénéralisation, comme celle qu'on peut trouver dans l'ouvrage de Dudley-Evans et St John :

In high uncertainty avoidance cultures, rules, plans and timetables are important, and uncertainty is avoided by making it clear what will happen and when - for example, in Greece, Belgium, France, Japan, Korea. In low uncertainty avoidance cultures, people are more relaxed about rules and procedures - as in Great Britain and Malaysia; uncertainty is acceptable so there is more flexibility about what happens and when. (1998: 68)

S'il est certain que de nombreux Français seraient quelque peu étonnés de se voir classés parmi les gens soucieux de la réglementation, et inversement pour les Anglais, la question fondamentale est de déterminer l'incidence de ce type de stéréotype sur la rencontre interculturelle. Si son rôle n'est pas aussi ouvertement nuisible que celui du stéréotype erroné, il n'est pas non plus dénué de tout effet contre-productif, dans la mesure où il subordonne l'identité première de l'individu à celle de sa culture d'appartenance et constitue, à cet égard, des filtres qui sont autant d'obstacles à l'intercompréhension.

\subsection{Le niveau du discours pédagogique : ou peut-on enseigner une façon de penser, d'agir, d'être?}

Comme nous avons pu le voir lors de la présentation de l'échelle des degrés de compétence culturelle, plus on avance, plus la notion de compétence se définit en termes d'état d'esprit, d'attitudes et de comportements psychologiques.

Il est aussi clair que l'objectif final si situe moins au niveau du repérage des artefacts observables d'une culture que d'une démarche personnelle conduisant in fine à un changement dans la façon de penser et d'appréhender l'Autre, ce qui conduit à son tour à un changement d'attitude et de comportement, de la façon d'être.

Et c'est là qu'il y a une interrogation de fond. Dans le contexte institutionnel de l'enseignement des langues, la didactique peut-elle prétendre à des objectifs aussi ambitieux? Nos enseignements peuvent-ils, dans le cadre des contraintes institutionnelles qui sont les leurs, opérer des modifications aussi profondes que le changement de la façon de penser et de la façon d'être? Ou, comme le résument les 
propos de Galisson au sujet de l'apprentissage des cultures, «Ce n'est pas parce qu'on le sait que l'on adhère » $(1991: 18)$.

La réponse est, bien entendu, nuancée en fonction du profil des apprenants, du profil de l'enseignant et du temps et des conditions de la réalisation des objectifs. Mais ce qui nous semble clair, c'est qu'il est illusoire de prétendre faire parvenir nos étudiants au degré de bien-être du savoir-être culturel, ou au degré d'efficacité opérationnelle implicite à la compétence du savoir-agir ou du savoir-interpréter.

Nous irons même plus loin. Pouvons nous supposer, par rapport à notre public universitaire, que le premier degré, celui de l'éveil à l'altérité, est un degré de compétence acquis? Nos propres travaux dans ce domaine nous conduisent à un certain pessimisme face à une telle hypothèse. En effet, une expérimentation réalisée systématiquement au début de chaque année universitaire sur les perceptions culturelles des étudiants $\mathrm{Bac}+3$, et plus, révèle une absence de recul et une forte dépendance quant aux stéréotypes comme outil d'analyse. Il semblerait donc, que le niveau du discours didactique à viser par l'enseignant se situe souvent à ce premier degré, celui de la sensibilisation, pour ensuite progresser vers le développement d'une capacité d'analyse fondée sur la mise en perspective interculturelle.

La question de la détermination du niveau du discours didactique est facilitée par la compréhension de «l'oignon d'Hofstede». Hofstede, un anthropologue culturel, a apporté une contribution importante à l'analyse ethnographique en définissant la culture en termes de couches visibles et invisibles, une approche qui peut aider l'enseignant à situer le niveau de son discours didactique.

Fig. 3 : L'oignon d'Hofstede

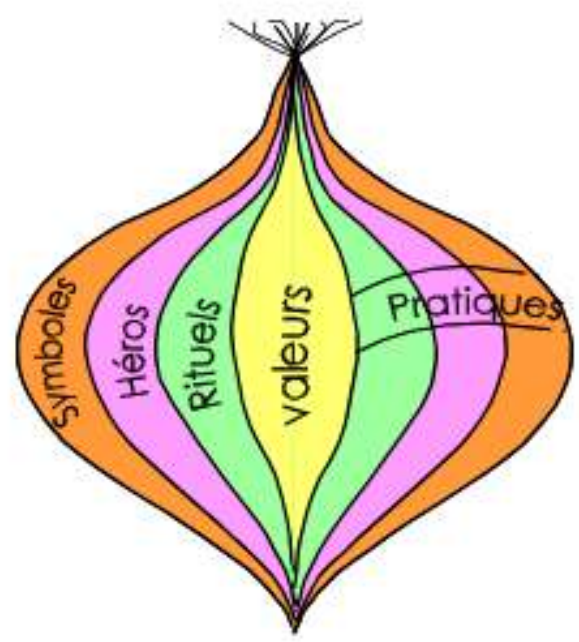

73 Les trois couches extérieures représentent les pratiques, ce qui est observable, ce qui est visible : les symboles, les héros, les rituels. Au cœur de l'oignon se trouvent les valeurs culturelles qui représentent la partie cachée, la couche invisible qui conditionne la pensée et la façon d'être d'une communauté.

En s'appuyant sur le concept de "visible » et « invisible», il nous semble intéressant d'envisager la problématique du niveau du discours didactique de la manière suivante : - Le discours institutionnel enseignant-apprenant viserait les deux premiers degrés de la 
culture professionnelle dans l'objectif de favoriser l'éveil à l'altérité culturelle et la constitution d'un capital de connaissances relatives à la partie "visible» de la culture d'une communauté qui peut servir de repère lors des phases initiales de la rencontre interculturelle.

- L'acquisition des débuts d'un savoir-faire culturel et d'un savoir-vivre culturel se fera de manière expérientielle et pragmatique à travers les stages professionnels et le vécu de l'expatriation.

- L'acquisition du savoir-être culturel et du savoir-agir culturel resteront tributaires de la maturation personnelle et professionnelle de l'apprenant.

\section{Conclusion : un bémol...}

En guise de conclusion, nous terminons sur une mise en garde contre ce qui nous parait comme un déséquilibre tendancieux dans le discours des chercheurs dans le domaine du culturel et de l'interculturel. Ce discours est, à nos yeux, trop orienté vers une représentation angélique de la rencontre interculturelle, avec une focalisation sur les seuls aspects positifs, beaux et valorisants.

Il s'agit d'une tendance que nous rangerons dans la catégorie des approches qui relèvent de la minoration de la différence culturelle où est gommée la nature fondamentalement déstabilisante, imprévisible et conflictuelle que peut revêtir la rencontre avec la culture de l'Autre.

Lisser les aspérités relatives aux phases de résistance, de confrontation, de rejet, de refus et de frustration, qui sont pourtant des parties intégrantes du processus, c'est mal outiller l'apprenant face à la réalité de la rencontre interculturelle. Et à ce titre, nous conclurons par une citation, parue il y a dix ans dans le numéro 5-6 de l'ASp, où Brace-Le Bigot soulevait déjà le problème :

Like most discovery processes, the challenge of cross-cultural learning involves disappointment, risk, frustration and bewilderment, as well as reward. If learners are to be authentically committed to in-depth pursuit in this domain, conflicts between cultural practices will inevitably be perceived. It is preferable to deal openly with such difficulties, for to avoid confrontation at all costs may result in reducing intercultural discovery to mere satisfaction with information for the sake of information. (1994: 217-223)

\section{BIBLIOGRAPHIE}

Abdallah-Pretceille, Martine. 1999. L'Éducation interculturelle. Coll. Que Sais-je ? Paris : Presses universitaires de France.

Beacco, Jean-Claude. 2000. Les Dimensions culturelles des enseignements de langue. Paris : Hachette.

Brace-Le Bigot, Suzette. 1994. « 'Cultural re-entry’ : Pedagogical application of a simple descriptive analysis of the dynamics of ccross-cultural encounter for students of international commerce ». ASp 5-6, 217-223. 
De Nuchèze, Violaine. 2001. «Y a-t-il une place pour la notion de prototype dans la réflexion sur la rencontre interculturelle?». In Isani, Shaeda (dir.), Culture \& Communication en milieu professionnel interculturel Publications CERELC, Grenoble : Université Stendhal Grenoble 3, 45-51.

Desjeux, Dominique. 1998. «L'Interculturel entre réalité et imaginaire ». Management \& mondialisation : la gestion des différences culturelles dans les entreprises, Paris : ENSPTT, 91-97.

Dudley-Evans, Tony \& Maggie Jo St John. 1998. Developments in English for Specific Purposes. Cambridge : Cambridge University Press.

Galisson, Robert. 1991. De la langue à la culture par les mots. Paris : CLE International.

Galisson, Robert \& Daniel Coste. 1976. Dictionnaire de didactique des langues. Paris : Hachette.

Gohard-Radenkovic, Aline. 2002. « La Culture universitaire comme culture en soi ». In Patchareerat Yanaprasart (dir.), Communiquer en milieu culturel. Neuchâtel : Université de Neuchâtel, 9-24.

Hall, Edward, T. 1966. La Dimension cachée (éd. française 1971). Coll. Points. Paris : Éditions du Seuil. Trad. Amélie Petita.

Hofstede, Geert. 1980. Cultures and Organizations, Software of the Mind. New York : McGraw Hill.

Isani, Shaeda. 2001. « Avant-propos ». In Isani, Shaeda (dir.), Culture et Communication en milieu professionnel interculturel. Grenoble : Publications CERELC, Université Stendhal Grenoble 3, 7-9.

Isani, Shaeda. 2004. « Popular films as didactic supports in ESP teaching - Selection criteria and ethical considerations ». In Petit, Michel \& Shaeda Isani (dir.), Aspects de la fiction à substrat professionnel, Coll. Travaux 2025. Bordeaux : Université Victor Segalen Bordeaux 2, 121-132.

Isani, Shaeda \& Donna Andréolle. 2001. «Langue de la culture et culture de la langue : la dimension didactique de la culture des langues de spécialité ». In Mémet, Monique \& Michel Petit (dir.), L'anglais de spécialité en France, Mélanges en honneur de Michel Perrin. Bordeaux : GERAS Éditeur, 225-236.

Klingseis, Katharina, Renate Rathmayr \& Sonja Schmid. 1997. « The role of linguistics in intercultural business communication, Working Papers of the $5^{\text {th }}$ Annual Conference on Marketing Strategies for Central and Eastern Europe, Vienna <http://www.wu.wien.ac.at/wwwu/ institute/slawisch/tafem.html>.

Laurent, André. 1998. « Culture du management et management interculturel ». Management \& mondialisation : la gestion des différences culturelles dans les entreprises. Paris : ENSPTT, 39-45.

Lehmann, Denis. 1993. Objectifs spécifiques en langue étrangère. Paris : Hachette.

Moles, André. 1971. La Communication. Paris : Centre d'études de la lecture.

Petit, Michel. 2002. «Éditorial ». ASp 35-36, 1-3.

Puren, Christian. 2002. « Perspectives actionnelles et perspectives culturelles en didactique des langues / cultures : vers une perspective co-actionnelle-co-culturelle ». Langues modernes 3, 55-71. Room, Adrian. 1987. Dictionary of Britain. Oxford : Oxford University Press.

Thévenet, Maurice. 1993. La Culture d'entreprise. Coll. Que sais-je ? Paris : Presses universitaires de France.

Van Ek, Jan, A. 1986. Objectives for Foreign Language Learning, Vol. 1 « Scope », Project n 12 « Learning and Teaching Modern Languages for Communication », Strasbourg: Council of Europe. 


\section{NOTES}

1. Se pose la question de la distinction à opérer entre la sociolinguistique et l'ethnolinguistique, deux disciplines qui sont souvent perçues comme étant peu différenciées. Pour les spécialistes, cependant, la sociolinguistique étudierait les sociétés civilisées à structures complexes et l'ethnolinguistique les sociétés primitives à structures simples. (Galisson \& Coste 1976 : 508)

2. L'ethnométhodologie : l'étude de l'organisation de la vie, y compris la langue.

3. Gordon Gekko, personnage emblématique du film Wall Street (1987) personnifie l'homme d'affaires rapace des années 80 . Sa devise «Greed is good, greed is right, greed works » est souvent utilisée pour décrire l'ethos de l'ère Reagan.

4. C'est nous qui soulignons.

5. Se pose, bien entendu, également la question du degré de spécialisation attendu de ce «nonspécialiste » qu'est l'enseignant de langues de spécialité par rapport au domaine de spécialisation de son apprenant. Il s'agit d'une question fondamentale qui a déjà fait l'objet de nombreuses publications et continue de susciter un vif intérêt notamment par rapport à la nécessité de réactualiser constamment le concept de "educated layman ", terme clé à ce propos, au vu de l'évolution des accès à l'information.

\section{RÉSUMÉS}

Cet article a pour objectif d'explorer le domaine de la culture professionnelle à travers une triple problématique. Premièrement, la définition d'une culture professionnelle qu'il analyse à travers l'exemple du monde de l'entreprise. Il examine, dans un deuxième temps, la notion de compétence de culture professionnelle définie en degrés de complexité croissante et, finalement, soulève quelques interrogations relatives à la didactisation de la culture professionnelle.

This article analyses the notion of professional culture in a three-fold perspective. To begin with, and using the corporate world for purposes of demonstration, it examines various defining components of professional culture. It then goes on to explore the notion of a professional cultural competence defined on a scale of increasing complexity and, finally, addresses some of the problems related to the transformation of "culture" into a didactic object.

\section{INDEX}

Mots-clés : compétence de culture professionnelle, culturalisme, culture de spécialité, culture d'entreprise, didactisation de la culture professionnelle, Hall (Edward T.), Hofstede (Geert), stéréotype

Keywords : corporate culture, culturalism, ESP culture, Hall (Edward T.), Hofstede (Geert), professional culture, stereotype, teaching professional cultural competence 
AUTEUR

SHAEDA ISANI 